\title{
Reflexiones sobre alteridad y técnica: la figura del robot humanoide en algunas transposiciones de la literatura al cine
}

\author{
Raúl Cuadros Contreras
}

“¿Por qué nuestros cuerpos deberían terminarse en la piel o incluir como mucho otros seres encapsulados en ésta?” D. Haraway

\begin{abstract}
Science fiction shows the most extreme forms of otherness that can be imagined. Those other beings and other worlds open the door to new ontologies and to the de-naturalization of opposed categories like organic/inorganic, natural/artificial. As a result we obtain new ways of thinking about identity and the definition of human being. This article explores this process by analyzing representations of technical advancement and its mediation between identity and alteration in some stories of this genre. With this in mind, the author takes the figure of the robot or cyborg as an example, as it appears in recent films, which show how it becomes humanized.
\end{abstract}

\section{Introducción}

El presente trabajo se inscribe en un cruce de miradas semióticas y filosóficas acerca de uno de los fenómenos más relevantes de la cultura contemporánea: la creciente presencia de la técnica y su mediación en las maneras que la humanidad tiene de construir una imagen de sí y su relación con los otros. Nos ocupamos aquí de las representaciones de la técnica y de su mediación en las relaciones entre identidad y alteridad en algunas narraciones del género de ciencia ficción.

Las transformaciones que se evidencian en los géneros, en especial en su tránsito a otros lenguajes y soportes, suelen testimoniar, más que efectos mecánicos de innovaciones tecnológicas, desplazamientos significativos, movimientos de la cultura (Steimberg, 1998). Nos interesa mostrar cómo en su 
paso al cine el género de ciencia ficción está expresando importantes rupturas en lo referente a las representaciones de la técnica y de sus relaciones con lo humano, algo que se evidencia en las maneras de transponer la figura del robot humanoide. ${ }^{1}$

La inquietud por el futuro se agudiza en la modernidad ${ }^{2}$ (Habermas, 1993) y se potencia con la sobremodernidad (Augé, 2004), algo determinante en la aparición del género de ciencia ficción. En éste momento esa inquietud tiende a revestir preocupaciones particulares relacionadas con la angustia por el estado de confusión ontológica, que se deja ver en la tendencia a la ruptura de las grandes clasificaciones dualistas de la tradición occidental (humano-animal, naturalartificial, hombre-mujer, orgánico-mecánico, vivo-inerte, etc), que posibilitaban el ordenamiento del mundo. El sentido pareciera amenazado pues, gracias a la mutabilidad técnica y social, es difícil establecer quién es el yo y quién es el otro. De este modo, se va imponiendo la indagación por la identidad y la alteridad más íntimas que estos cambios amenazan y confunden. Las huellas de esa indagación han dejado su marca en el género.

Las figuras de los monstruos tienen que ver ante todo con eso, con la emergencia de criaturas liminales que ponen en duda las fronteras de la propia especie y que llevan a la discusión de sus relaciones con otras especies y con otros tipos de seres. El robot humanoide ${ }^{3}$ aparece en éste contexto como una figura monstruosa, porque evidencia la confusión fundamental entre lo humano y lo técnico, a veces de manera más explícita, como sucede con la figura del cyborg. ${ }^{4}$ Pero, en términos generales, el hecho de ser humanoide, ante todo en

\footnotetext{
${ }^{1}$ Se denomina transposición al pasaje de un texto a otro género, otro lenguaje u otro soporte (paso de la literatura al teatro, de la literatura al comic, de la literatura al cine, del cine al comic, etc.). En el estudio de este fenómeno semiótico se trata de apreciar principalmente lo que acontece con las continuidades y variaciones semánticas que tienen lugar con esos pasajes, de establecer qué tipo de mirada se ha hecho del texto, si ha transitado por la vía de una lectura de género o si se ha inaugurado otro tipo de encadenamiento discursivo, fenómenos que dejan ver como la cultura se ve a sí misma o se reinterpreta en distintos momentos históricos (Steimberg 1980, 1998; Traversa 1986).

${ }^{2}$ Habermas comenta cómo la modernidad hace aparecer la conciencia histórica, que se corresponde con la noción de la simultaneidad cronológica de evoluciones históricamente simultáneas y con la nueva experiencia del progreso y de la aceleración de los acontecimientos históricos, así como con la apertura al futuro. A propósito comenta a Hegel: (...) "caracteriza a la actualidad como un momento de tránsito que se consume en la conciencia de la aceleración del presente y en la expectativa de la heterogeneidad del futuro (...) Como el mundo nuevo, el mundo moderno se distingue del antiguo por estar abierto al futuro, el inicio que es la nueva época se repite y perpetúa con cada momento de la actualidad que produce de sí algo nuevo" (Habermas 1993:17).

${ }^{3}$ Robot humanoide es un tipo de robot con forma humana, dado que existen muchos otros tipos de robots que no tienen esa forma. Se trata de una definición muy general, de modo que puede tratarse de robots clásicos (metálicos) o de androides.

${ }^{4}$ Cyborg (ciberorganismo) es una palabra inventada por la ciencia en 1960, que la define como un ser humano hipotético, constituido con miras a adaptarse a la vida de ambientes no terrestres mediante la sustitución de partes de su cuerpo por órganos artificiales. En la CF cyborg es todo ser híbrido entre humano y máquina.
} 
el caso del androide, ${ }^{5}$ exhibe el mismo problema fundamental: la confusión ontológica, que se agudiza toda vez que los robots presentan crecientemente rasgos de subjetividad.

\section{Consideraciones generales}

\section{Género, identidad, alteridad}

Los mundos de la ciencia ficción (CF en adelante), que suelen ser otros mundos, están poblados por otros. Esta circunstancia conlleva varias implicaciones:

1. Esos otros y otros mundos configuran distintas maneras de concebir ontologías (otras naturalezas, otras leyes físicas, otros tipos de seres, otras sociedades, otros tipos de relaciones entre seres sociales), lo que en rigor implica el abandono de una ontología.

2. Esos otros tipos de seres configuran múltiples maneras de representar imaginariamente la alteridad, algo que cuenta como una apertura en el camino de la desnaturalización ${ }^{6} \mathrm{y}$ de ruptura con los dualismos radicales de la tradición occidental, pues esos seres suelen integrar polaridades típicas (natural-artificial, humano-animal, orgánico-inorgánico, hombre-mujer), si bien esto no excluye las miradas colonialistas e imperialistas.

3. Lo que resulta de todo esto son distintas maneras de imaginar la identidad. Lo humano resulta algo problemático, que adquiere sus contornos en función de esos otros y que, por constante oposición y afinidad, resulta re-construido incesantemente, es decir, des-naturalizado, des-ontologizado.

\footnotetext{
${ }^{5}$ Androide significa, en rigor, ser con apariencia de humano macho, pero en la CF androide se usa como ser humano artificial hecho de alguna sustancia orgánica.

${ }^{6}$ Porque naturalizar es la operación ideológica más frecuente, manera de representarse el mundo como algo dado de una vez, asumiendo los modos de ser propios del país, sociedad o cultura en la que se vive como los legítimos, preferibles, auténticos o verdaderos. Por esta razón se dan por naturales los valores, los hábitos, los tipos de relaciones sociales propios de la sociedad en que se vive (Said 2006). El género de CF, por su tendencia a imaginar formas completamente distintas, no sólo ya de relaciones sociales, sino de sociedades completas, de mundos naturales y sociales, de modos de ser humanos y de otros seres posibles inteligentes y sensibles, ayuda a desnaturalizar, a pensar que son posibles otras maneras de ser y, en consecuencia, que los modos de ser que conocemos pueden devenir en otros. Ante todo, la CF ayuda a pensar la propia naturaleza y el hombre como no naturales y como no dados de una vez y para siempre: a la naturaleza, que como ha mostrado Donna Haraway (1991) también es una construcción social depositaria de prejuicios de todo tipo y no un dato puro de observación como pretenden los científicos; y al hombre como un ser que se construye y reconstruye permanentemente y que adquiere distintos contornos según se lo vea en distintos tipos de relaciones con otros tipos de seres, peculiaridad que se evidencia si se enfatiza su relación irrenunciable y constitutiva con la técnica.
} 
La palabra monstruo procede de la palabra latina monstrum, que significa augurio, de modo que los animales y los seres humanos que nacían deformes eran considerados como advertencias divinas de desgracias futuras. Así, en la Edad Media, cuando persistía la homología aristotélica entre fantasía y experiencia (Agamben, 2001), era común pintar o esculpir a los monstruos en los portales de las iglesias, como amonestaciones, como avisos sobre la vida real. Los monstruos aparecen vinculados también a la transgresión de límites normales, de una ley interior, de una ley social o de un rito (Ciocchini y Volta, 1992). Todos los grandes prototipos de monstruos son al mismo tiempo desafíos a la regularidad de la naturaleza y a la regularidad de la inteligencia humana. Por ello, el gran principio de la teratología está basado en el estudio de la irregularidad, de la desmesura (Calabrese, 1989), pues los monstruos son siempre excesivos y escapan a la perfección natural, que es una medida media. Imperfecto y monstruoso es también aquello que sobrepasa los límites de otra medida media, la espiritual. Mediedad y perfección son casi sinónimas, de allí que el monstruo suele ser un ser no sólo anormal sino generalmente negativo.

Las sociedades más normalizadas suelen establecer homologías entre las diversas categorías de valor (ética, estética, morfológica, tímica) y, en períodos de mayor "orden", homologaciones rígidas entre los términos positivos y entre los términos negativos de las cuatro categorías. De esta manera, por ejemplo, lo que se considera físicamente conforme será también bueno, bello y portador de euforia (Calabrese, 1989). No obstante también se producen rupturas, derivaciones, inversiones, combinaciones con respecto a estas homologaciones. Los monstruos contemporáneos corresponderían a ciertos cambios producidos en el régimen de las homologaciones. Lo propio de estos sería la suspensión, la anulación, la neutralización de las homologaciones de las categorías de valor. Se caracterizan por su inestabilidad y por su informidad, asunto de la mayor importancia dado el carácter social de la teratología, pues estas categorías corresponderían también a la sociedad contemporánea.

Ahora bien, la CF, que exhibe todas estas características en el tratamiento de los monstruos, también tiende a replantear su papel, aprovechando su condición liminal para abrir paso a nuevas posibilidades.

Los monstruos han definido siempre los límites de la comunidad en las imaginaciones occidentales. Los centauros y las amazonas de la Grecia antigua establecieron los límites de la polis central del ser humano masculino griego mediante su disrupción del matrimonio y las poluciones limítrofes del guerrero con animales y mujeres. Gemelos no separados y hermafroditas eran el confuso material humano en la temprana Francia 
moderna que basaba el discurso en lo natural y en lo sobrenatural, en lo médico y en lo legal, en portentos y en enfermedades, todo ello de suma importancia para el establecimiento de la identidad moderna. Las ciencias evolucionistas y del comportamiento de los monos y simios han marcado las múltiples fronteras de las identidades industriales de final de siglo. En la ciencia ficción feminista, los monstruos cyborgs definen posibilidades políticas y límites bastante diferentes de los propuestos por la ficción mundana del Hombre y de la Mujer (Haraway, 1991).

En este contexto aparecen las criaturas fronterizas que, como en las ciencias y en la sociedad contemporánea (simios, cyborgs, mujeres) (Haraway, 1991), han actuado como desestabilizadoras de sus respectivos órdenes. En la CF esas criaturas fronterizas y sus modos de ser revulsivos pueden contar como augurios, como signos de mundos posibles (Haraway, 1991, 1992). En la CF son monstruos entonces aquellas criaturas fronterizas u "otros inapropiados" que no pueden encasillarse dentro de las clasificaciones establecidas, naturalizadas, del yo y del otro y que abren posibilidades a una relación deconstructiva, relacional y crítica con la identidad. No obstante, es preciso recordar que el género ha estado involucrado con el colonialismo y con el imperialismo, como en su tiempo lo estuvo la literatura de viajes. ${ }^{7}$ También lo está con la producción social de metáforas literales y cuerpos poéticos de ordenamientos sociales de alta tecnología.

\section{Distintas representaciones de la técnica}

Un lugar muy relevante en la imaginería del género lo ocupan las distintas representaciones de la técnica en sus complejas relaciones con la identidad y la alteridad. Una actitud muy marcada fue la del rechazo a las máquinas, sobre todo en el apogeo de la revolución industrial, ya que éstas se percibieron como amenazas en cuanto aparecían como producciones humanas que podían llegar a oponerse a lo humano. Incluso los robots, en algunos momentos, han representado ese temor de la era de las máquinas industriales por su capacidad

\footnotetext{
7 También en algunos momentos ha fomentado imágenes que han adquirido la forma de una "mitología", de una representación naturalizada de un punto de vista ideológico, como la que Barthes (1985) denomina la mitología marciana, que consiste en una manera estrecha de imaginar al otro, consiste en un antropomorfismo y en un antropomorfismo de clase. Corresponde al mito de lo idéntico, Marte sería la Tierra y a la vez el cielo de donde proviene la muerte atómica. El mito del doble, en el que aparece como una tercera mirada, como un juez, que viene a presentar el conflicto entre Este y Oeste como maniqueo. Así, la mirada de los marcianos correspondería en verdad a la de la Tierra aunque se la presente bajo la forma de una supernaturaleza porque en el cielo está el terror.
} 
para actuar con independencia de los hombres. ${ }^{8}$ Pero también ha habido otras actitudes de gran entusiasmo, que tuvieron también su correlato en las vanguardias artísticas -como en el futurismo- y que se manifestaron en el género como historias de superciencia. En otros momentos, el deseo ha aparecido asociado a las máquinas, a la fascinación tecnológica o a las identificaciones de la máquina con lo femenino, como en Metrópolis (Fritz Lang, 1927), donde la robot aparece como seductora y a la vez como encarnación de una poderosa amenaza.

Una expresión de los cambios en la percepción de la técnica y de su relación con lo humano es la construcción de una figura tardía en la historia de la CF: la figura del cyborg. El cyborg parece querer recuperar para el hombre el dominio sobre las cosas, dominio que parecía perdido en la medida en que las máquinas aparecían como superiores o como independientes de él, de manera que las máquinas ya no estarían afuera ni contra el hombre y, así, el hombre no sería más un extraño en un mundo creado por él. Igualmente, el cyborg representa la capacidad mayor de su adaptación al medio artificial de vida (Kagarlitsli, 1977; citado por Daniel Link). La cultura popular intensifica la corporeidad imaginando todo tipo de intercambios con las máquinas hasta llegar a sintetizarlos en la figura del cyborg: un cuerpo con músculos humanos y partes mecánicas que aumenta su capacidad física y sexual (Springer 1996), borrándose así todos los límites entre lo humano y las máquinas y dando lugar a una nueva idea de yo, no unificado, híbrido.

\section{Distintas figuraciones del robot en la ciencia ficción}

Los hechos históricos han condicionando en cierta manera el género, agudizando las tensiones hombre-máquina y ciencia-fantasía. Dichas tensiones se reflejan en las distintas formas de imaginar los robots. La obra de Karel Capek Los robots universales de Rossum (1966) tenía de fondo tanto la agudización de la lucha de clases como el padecimiento de los rigores de la primera guerra mundial.

\footnotetext{
${ }^{8}$ Lo que se conoce como el síndrome de Frankenstein, Asimov (1999: 171-199), explica como las máquinas -entendidas en sentido amplio- siempre han despertado un sentimiento ambivalente de amor y odio, y que el odio está asociado a los peligros que éstas representan por su desarrollo acumulativo que las hace aparecer como imparables y tendientes a romper el control de los humanos. No obstante insiste en que hay odios o miedos de distinto tipo hacia las máquinas, que de hecho la humanidad por más que tema a los daños secundarios que éstas representan no ha tendido por regla a desechar las bondades de las máquinas. Sin embargo, aclara que existe cierto temor que tiene un origen más antiguo y profundo, y que ha sido representado imaginariamente en los mitos de todos los tiempos (mitos de reemplazo). El temor al cambio irreversible que se opone al cambio cíclico -el cual sí es querido y hasta muy deseado por los hombres- y al reemplazo que en muchos casos este conlleva. El temor al cambio irreversible y el temor a la pérdida de control se conjugan en la imagen del robot, figura que representa la mayor posibilidad de pérdida de control y al tiempo la posibilidad de ser reemplazados por un hijo superior, como Urano por Cronos y Cronos por Zeus. Frankenstein representa ante todo la figura de la pérdida de control y la posibilidad del aniquilamiento por la propia creación.
} 
La visión que Capek puso a circular en 1920 cuando introdujo por primera vez la palabra robota, que significa esclavo en checo, es por completo pesimista. La primera CF estadounidense, la de comienzos del siglo XX, es en cambio predominantemente optimista (Capanna, 1966) -algo que sólo cambiaría más tarde con la Gran Depresión-, aunque también incluyera desde el comienzo a la vertiente pesimista que, como afirma Asimov, estuvo desde los inicios tanto en Europa como en EEUU. ${ }^{9}$

Una tendencia fuerte es la representada por el propio Asimov (también por Arthur Clarke y James Hogan), quien construye verdaderas utopías, como parte de su estrategia para desacreditar el complejo de Frankenstein, en las que el robot representa el progreso incesante de la humanidad y en las que este es presentado como inmanentemente bueno, inofensivo y útil. Para construir esta imagen Asimov elabora con John Campbell las famosas tres leyes de la robótica, ${ }^{10}$ que representan un mecanismo insalvable de seguridad en la configuración de sus robots y alrededor de las cuales construye la trama y confiere verosimilitud a sus historias. Otra tendencia es la representada por Philip K. Dick, quien tiene una visión apocalíptica de los robots y construye distopías en las que predomina el creciente proceso de indistinción entre estos y los humanos. Una mirada distinta la encontramos en el subgénero Ciberpunk, en el que, por momentos, parecería que se aspirara no sólo a eliminar el miedo a las máquinas sino a entregarse con fascinación a ellas. En este subgénero se destaca la tendencia a la desaparición del cuerpo como el lugar donde anida el deseo, para diluirse en los mundos virtuales a los que la computadora permite acceder. Entre los personajes de estas obras predominan cyborgs, humanos que cambian de rostro con frecuencia usando prótesis que eligen a su gusto y hasta fantasmas electrónicos que parecen no tener ningún cuerpo como soporte.

Durante mucho tiempo la televisión y el cine prolongaron la visión apocalíptica reviviendo el síndrome de Frankenstein. No obstante, no se puede afirmar que haya predominado esa única tendencia, antes bien, con frecuencia

\footnotetext{
${ }^{9}$ Asimov comenta que, si bien el optimismo y el pesimismo combatieron entre sí en la CF entre 1926 y 1959 -período de apogeo de las revistas de CF-, el optimismo se impuso desde 1938 cuando John W. Campbell hijo asumió la jefatura editorial de Astounding Science Fiction. Campbell combatió la imagen del científico loco y de la máquina destructiva y luchó por presentar una imagen positiva de la ciencia y de la técnica. Como parte de ese esfuerzo reivindicativo, él mismo escribe una serie de historias sobre robots en las que se combatía el mito de Frankenstein presentando a los robots como "sirvientes, amigos y aliados de la humanidad". No obstante, anota Asimov que en los años 60 volvió a predominar el pesimismo (Asimov 1999:158-159, 162-163, 181-182).

${ }^{10}$ 1. Un robot no debe dañar a un ser humano o, por su inacción, dejar que un ser humano sufra daño. 2. Un robot debe obedecer las órdenes que le son dadas por un ser humano, excepto cuando éstas órdenes se oponen a la primera ley. 3. Un robot debe proteger su propia existencia hasta donde esa protección no entre en conflicto con la primera o la segunda ley.
} 
aparecen figuraciones que no se apegan a uno u otro de los dos extremos, en las que tiende a predominar la ambivalencia y en las que aparecen gran cantidad de nuevos matices. ${ }^{11}$

\section{Análisis del corpus}

\section{Deseo y subjetividad}

En las transposiciones de películas analizadas que se presentan a continuación aparece el deseo como lo determinante, el deseo como elemento común a la representación del robot y como rasgo constitutivo de lo humano.

Blade Runner (Ridley Scott, 1982): En este filme el gran tema que marca la diferencia sustancial con respecto a la novela en la construcción de la figura del androide es el apego a la vida. Podemos leer este tema en la concepción ética de Spinoza (1980) para quien "cada cosa, en tanto que es en sí, se esfuerza en perseverar en su ser". Lo que caracteriza a los replicantes -así se denomina a los androides en la película- es justamente su deseo de perseverar en su ser. En el filme los replicantes pertenecen a una generación muy singular, los Nexus 6 , que han sido diseñados atendiendo a las más deseables cualidades humanas: son bellos, fuertes, ágiles, muy inteligentes (superiores a la media humana), son capaces de desarrollar sentimientos humanos (aunque al principio carezcan de algunos muy elementales, gozan de singularidad y tienen conciencia de sî). Pero han sido fabricados con una limitación muy importante: sólo pueden vivir 4 años. La razón de esta limitación está justamente en la capacidad que tienen de desarrollar sentimientos humanos. Los Nexus 6 han venido a la Tierra, arriesgándose a ser cazados, porque buscan remediar esa imperfección. Sufren ante la idea de la muerte inminente, quieren vivir y luchan incansablemente por defender su vida. Pero hay algo más. Al final, el replicante Roy, que hace las veces de líder del grupo rebelde, cuando tiene la posibilidad de matar a su cazador -el mismo que ha eliminado al resto del grupo y a su compañera- no le quita la vida sino que lo salva de una muerte que parecía inevitable. Su muerte se acerca, siente ya el desfallecimiento final, y entonces se le ve muy triste, se

\footnotetext{
${ }^{11}$ Contra la idea tan difundida de que el cine de CF se ha desentendido de las grandes preocupaciones (sobre el universo, la naturaleza, la humanidad) que han caracterizado a la literatura de CF y de que, al fin y al cabo, no es más que un género de fantasía emparentado con el de horror, es posible mostrar cómo, explorando su propia fantasía sobre otros mundos naturales y sociales en toda una variedad de tipos de seres y de monstruos, el cine de CF da continuidad a la reflexión sobre esos grandes asuntos y ha dado lugar a otras preocupaciones, como las relativas a la ingeniería genética, las relaciones de género, la eutanasia, la inteligencia artificial, la automatización, entre otros, e incluso ha contribuido a que haya una mejor conciencia pública sobre estos (Telotte, 1995).
} 
lamenta por la pérdida de las cosas bellas que ya no podrán ser, se escapa de su lado una paloma blanca y muere. Sus últimas palabras son:

He visto cosas que los humanos ni se imaginan, naves de ataque incendiándose cerca del hombro de Orión, he visto rayos de mar centelleando cerca de la puerta de Tannhauser. Todos esos momentos se perderán en el tiempo como lágrimas en la lluvia. Es hora de morir.

Roy desea perseverar en su ser, quiere vivir, quiere realizar todo cuanto pueda su potencia de ser, de la cual se siente orgulloso pues se sabe superior, y eso hace que su tristeza sea mayor, la insoportable fatalidad de tener un límite impuesto artificialmente y al que nunca se resignó. En el film -en las dos versiones- esto pasa a primer plano, los replicantes son erigidos en sujetos y se nos deja oír su voz, la cual nos habla de su propia perspectiva de sí .

Inteligencia artificial (Steven Spielberg, 2001): Una jugada de Martín (el niño humano) dispara el deseo de David (el niño robot). En otro intento por molestar a David y por competir con él, un él al que reconoce formalmente como un Meca pero al que no logra asimilar del todo como tal, Martín le pide a Mónica (su madre) que les lea el cuento de Pinocho. David queda fascinado con la historia, es interpelado como sujeto de deseo por la narración, de manera tal que ahora su camino está trazado, debe encontrar al Hada Azul para que esta lo convierta en un niño de verdad, de modo que así su madre pueda amarlo.

El film pone en primer plano la "naturaleza" de un sujeto deseante, pero se trata de una forma de sujeto ya extinta. Lo que aparece en la película es un sujeto que es capaz de identificar su deseo con el fantasma, ${ }^{12}$ de allí que "hechos" y "ficciones" puedan entrecruzarse y tener sentido. La imaginación en David no significa lo que significa para nosotros, la fantasía es para él lo que posibilita el encuentro entre experiencia y conocimiento. De allí resulta que el sueño pase a jugar un papel central, como en la Antigüedad, el sueño

\footnotetext{
${ }^{12}$ Giorgio Agamben explica cómo es que tiene lugar la destrucción de la experiencia a partir de su subsunción y transformación en la noción de sujeto moderno. Según Agamben, antes de la modernidad no existía el sujeto, los sujetos de la experiencia y del conocimiento se encontraban separados, de manera que la experiencia correspondía al mundo de lo múltiple y el conocimiento al mundo de lo único. La experiencia no estaba sometida al método ni tenía nada que ver con el conocimiento, pues no era algo previsible, tenía que ver con un padecer, con algo que no podía anticiparse, algo cercano a la proximidad de la muerte. En ese contexto la fantasía tampoco era lo que es ahora, algo relacionado con lo irreal y meramente subjetivo. Al contrario, antes la fantasía era la coincidencia de lo subjetivo con lo objetivo, de lo interno con lo externo, y la mediadora entre ambos: "Lejos de ser algo irreal, el mundus imaginabilis tiene su plena realidad entre el mundus sensibilis y el mundus intelligibilis, e incluso es la condición de su comunicación, es decir, del conocimiento" (Agamben, 2001).
} 
se encuentra en él vinculado con la verdad. Y el deseo ${ }^{13}$ significa también algo distinto. El fantasma o la fantasía es el verdadero origen del deseo, es también el mediador entre el hombre (en este caso el niño robot) y el objeto, y es al mismo tiempo la "condición de apropiabilidad" del objeto del deseo y, por ello mismo, de su satisfacción. De allí que en esa tradición, de la cual resurge esta noción de sujeto, el fantasma es al tiempo el sujeto y el objeto del eros. En ella el amor ${ }^{14}$ tiene un carácter fantasmagórico y es por ello que puede realizarse y tornarse en experiencia.

David deviene sujeto en la búsqueda del Hada Azul, su deseo ha sido movilizado y compelido a realizarse. Quiere ser humano para alcanzar el amor de su madre y para ello se embarca en la búsqueda del Hada. No obstante, lo que encuentra en la travesía es su propia subjetividad, que aparece por efecto de la identificación de su deseo con la fantasía. No ha tenido lugar una transformación fantástica de sus ser, pero, por efecto del encuentro con la fantasía, se ha operado una transformación en su subjetividad. Lo que era posibilidad se actualiza como realización, David llega a ser un niño con un mundo interior complejo gobernado por el deseo.

Yo robot (Alex Proyas, 2004): En este filme no hay androides y los robots tienen formas apenas humanoides, en eso coincide con la novela. Pero la diferencia la pone Sony, cuyo cuerpo es metálico pero quien tiene un rostro expresivo a diferencia de los otros robots. Sony ha sido creado por el Dr. Lanning para cumplir una misión muy especial en contra de una conspiración de las máquinas contra la humanidad. Lanning, que le había enseñado las emociones humanas, le hace prometer que lo va a ayudar a cumplir un propósito. Sin embargo, el doctor engaña al robot, pues le ha hecho jurar que lo ayudará a matarse. Sony es la pieza clave en la cadena de pistas para que Spooner (el detective cyborg) resuelva el caso a favor de la humanidad.

Sony es un robot bastante humanizado, alberga recuerdos y es capaz de experimentar emociones humanas; tiene capacidad para aprender y evolucionar autónomamente y tiene impresas las tres leyes de la robótica, pero bajo un mecanismo que le permite usarlas discrecionalmente. Sony desea tener un lugar en el mundo de los humanos y está obsesionado con aprender el comportamiento

13 "La expropiación de la fantasía del ámbito de la experiencia arroja sin embargo una sombra sobre esta última. Esta sombra es el deseo, es decir, la idea de una apropiabilidad e inagotabilidad de la experiencia. Pues según una intuición que ya estaba presente en la psicología clásica y que será completamente desplegada por la cultura medieval, fantasía y deseo están estrechamente ligados” (Agamben 2001:27).

14 "Porque el amor no es una oposición entre un sujeto deseante y un objeto del deseo, sino que posee en el fantasma, por así decir, su sujeto-objeto, los poetas pueden definir sus rasgos (en oposición a un foul amour que sólo puede consumir su objeto sin llegar nunca a unirse verdaderamente a él, sin hacer nunca esa experiencia)" (Agamben 2001: 28-29). 
humano. Es así como tiene lugar la escena en la que se interesa por aprender el significado de un guiño. Sony recibe la explicación: el guiño es un gesto de confianza entre seres humanos. Al poco tiempo demuestra saber usarlo, en un momento de mucha tensión en el que él, Susan (coprotagonista) y Spooner se encuentran rodeados por los robots dirigidos por VIKI, la computadora que se ha rebelado interpretando las 3 leyes bajo el criterio de que los seres humanos son incapaces de cuidar de sí mismos, razón por la cual ha decidido tomar medidas extremas contra ellos. Sony finge estar del lado de VIKI, toma a Susan y amenaza con matarla si Spooner le dispara, y les exige que salgan escoltados por él para entregarlos para ser procesados, pero en ese momento le hace un guiño al detective indicándole que puede disparar mientras él protege a Susan. Spooner entiende y coopera, entonces Sony se une al ataque contra los robots.

Si en la novela prevalece la mirada utópica que atribuye la garantía del progreso humano a la actuación de los robots, y si, en principio, en la transposición aparecía la visión contraria (la distopía robótica) al final la actuación de Sony y su feliz convergencia con el cyborg Spooner sugieren otra cosa. De hecho, Sony representa la posibilidad de la continuidad humana en otro tipo de ser por no estar constreñido por un mecanismo insalvable y por su capacidad para evolucionar y aprender las emociones humanas, pero, ante todo, por su deseo de pertenecer al mundo de los humanos. Se impone así la ambivalencia.

El hombre bicentenario (Chris Columbus, 1999): Tanto en el texto literario como en la transposición cinematográfica es patente el deseo del robot Andrew por hacerse humano, y se muestra el proceso por el cual llega a serlo. No obstante, el acento está puesto en aspectos distintos en uno y otro caso. En la novela prevalecen ante todo sus desarrollos intelectuales: escritor una historia de la robótica, investigador, fundador de una nueva ciencia y empresario de los productos tecnológicos que de ella se derivan. De hecho, en el filme Andrew no aparece en primer plano como sujeto de la actividad científica, él diseña y colabora con Rupert Burns (diseñador de robots), pero es éste último quien aparece como científico. En el filme lo que más se destaca es el desarrollo social y moral de Andrew, como el aprendizaje del lenguaje coloquial (chistes, vulgaridades e implicaciones) y la asunción de su propia subjetividad. Esto se revela cuando Andrew, que siempre se refería a sí mismo como "uno" "“a uno le complace servir"), sin darse cuenta empieza a hablar en primera persona y habla de sí mismo como yo una vez su dueño (Martín) le concede la libertad. Sin embargo, cuando enfrenta el fallo negativo de la Asamblea Mundial respecto a su reconocimiento como ser humano para casarse con Portia (bisnieta de Martín), vuelve automáticamente, en ese momento de turbación, a decir "a uno le complace servir". También se destaca el establecimiento de vínculos afectivos 
con el dueño y su familia, llegando hasta el enamoramiento y la relación de pareja con Portia. Ésta dimensión sexual y erótica, que no aparece en absoluto en el texto fuente, tiene gran peso en la transposición. Andrew mantiene desde siempre gran inquietud por esa dimensión de lo humano. Por eso, cuando Rupert Burns le anuncia que ahora sí va a ser un "hombre completo", siente gran felicidad y profiere un discurso romántico e intenso en el que se revela que percibe lo sexual como fusión, como disolución. Esa nueva transformación en su funcionamiento aparece de hecho como la consumación de su conformación en sujeto. Sólo en éste momento se decide a enfrentar a Portia y a presionarla para que reconozca que lo ama y desista de su matrimonio con otro. La consumación de ése nuevo estado es presentada en el texto bajo la forma de la desmesura: Andrew ha pasado una noche deliciosa con Portia y en la mañana tiene mucha hambre y come sin parar.

Lo que deja en evidencia la película es que este devenir en sujeto humano de Andrew, en todas las dimensiones, es el resultado de un proceso de autoconstrucción. Así, si no se es humano por el simple hecho de nacer como miembro de la especie (asunto meramente contingente), también se plantea la posibilidad de llegar a ser humano superando la contingencia de haber sido antes otro tipo de ser (una máquina no viviente). Con esto no sólo se acentúa el carácter no natural de la condición de ser humano, sino que se destruye la polaridad ancestral natural-artificial y se elimina por completo la noción esencialista, ontológica, de ser humano. Ser humano aparece como un asunto de poiesis más que de ontología. Nos encontramos con un humanismo materialista posmoderno, en el que esa condición de perfectibilidad y autoconstrucción no se restringe a una búsqueda espiritual sino que presupone la dimensión corporal y la posibilidad material de una transformación constante como algo que compromete en primer lugar al cuerpo. Andrew pasa de robot a cyborg, y de cyborg a humano. Andrew se produce a sí mismo y llega a ser humano porque es capaz de devenir en ser orgánico, sensible, sexuado y mortal.

\section{Enunciación, sensibilidad, ideología}

En las cuatro transposiciones anteriores nos encontramos con que la historia es narrada desde el punto de vista del robot o se lo focaliza, y se nos ofrece su visión de sí mismo y de los humanos. Se trata del rasgo más constante y más significativo en las rupturas que han tenido lugar con respecto a los textos fuentes y quizá con respecto al género. Se trata de un desplazamiento enunciativo e ideológico que se introduce mediante alguna variación diegética importante: se focaliza un personaje humano que luego se devela como robot. En Blade Runner, Deckard 
(el detective que caza a los replicantes) pasa a ser un replicante. En Inteligencia artificial se transforma la figura del robot mediante la incorporación de un niño robot (David) y se narra desde su punto de vista. Lo mismo ocurre con el robot que se hace humano en El hombre bicentenario. O, como en Yo robot, se invierte el punto de vista argumentativo e ideológico y se introduce la voz de un cyborg (Spooner) que expresa la posición contraria a la expresada en el texto fuente.

La lectura de época ${ }^{15}$ saca de entre los textos fuentes otras voces y otras subjetividades, y esas otras subjetividades permiten ver otros modos posibles de ser. La mirada del robot posibilita ver lo humano de otra manera, la mayoría de las veces nos presenta verdaderas imágenes de horror. Lo humano aparece bajo otra luz, se trata de un distanciamiento que permite ver lo que no se suele ver, pues se desnaturaliza el lugar privilegiado de "lo humano" como potestativo de nuestra especie, el cual pasa a ser ocupado por otro tipo de ser. Por éste movimiento se pueden apreciar las actitudes de los seres humanos como feas, innobles, despreciables; pero, al mismo tiempo, ese desplazamiento asegura la emergencia de una humanidad nueva, de otra subjetividad posible en otros tipos de seres.

Esa variación abre paso a la presencia de otras subjetividades, algunas a veces sólo insinuadas en los textos literarios, otras impensables siquiera en ellos. Se trata de un elemento común a las cuatro transposiciones que está determinado por la lectura de época, que a su vez lastra las insistencias de nuevas sensibilidades. Es como si, para poder apreciarse, lo humano requiriese de un distanciamiento. Un artefacto humanizado nos presenta su visión de nuestro mundo, como si lo humano no pudiera anidar más en las formas cristalizadas de la subjetividad y precisara de una transformación radical. La continuidad de lo humano en sus creaciones robóticas, algo que puede ser percibido como una calamidad, como la consumación de la deshumanización y hasta de la destrucción de todo vestigio de humanidad, es presentado como algo legítimo, que, además, puede aparecer como una posibilidad de redención, mediante la cual lo humano es salvado no sólo de su extinción sino de su degeneración en cuanto puede presentarse como una superación, ante todo como la posibilidad de la reconciliación con la alteridad. Así aparece muy claramente al final en Inteligencia artificial, cuando sólo queda David y es él el llamado a rehacer esa relación con los extraterrestres, pero se avizoraba ya en Blade Runner (en la versión de 1982) mediante la posibilidad de la relación de pareja androide-humano, y con la posibilidad de la relación

\footnotetext{
${ }^{15}$ Noción inspirada en de una idea de Benedetto Croce, que insiste en el carácter histórico y político de toda lectura que opera sobre un texto (un fragmento textual del pasado), la cual tiene lugar siempre desde los intereses y representaciones de un narrador enraizado en el presente (Steimberg 1998:97, 98).
} 
entre androides en la versión del director -posibilidad que aparecía ya en el texto fuente pero que no revestía el carácter promisorio que adquiere en el filme de 1982. Sin embargo, en ambas sólo se deja planteada esa posibilidad al mismo tiempo que se enfatiza una visión pesimista con respecto a los humanos. En El hombre bicentenario, la reconciliación se consuma por el vínculo amoroso entre Andrew y Portia, mientras que en Yo robot la reconciliación tiene lugar-al menos como el comienzo de una nueva relación- entre un humano, un cyborg y un robot bastante humanizado. En otro sentido, la idea de la reconciliación de lo humano con sus construcciones tecnológicas puede ser entendida como la posibilidad de la reconciliación de lo humano con la naturaleza que, abandonando la condición de objeto inanimado a la que ha sido sometida, produce una subjetividad nueva que puede armonizarse con lo humano (Adorno y Horkheimer, 1994; Wellmer, 1993: 33 ).

\section{Ontología, técnica, poiésis}

En los filmes estudiados se destaca la constatación de la desnaturalización de lo humano y el predominio de la poiésis ${ }^{16}$ sobre la ontología. Primero se presenta una ampliación del espectro ontológico, con la presencia de otros seres, robots, superjuguetes, supercomputadoras, cyborgs de distinto tipo. No obstante, los textos que nos ocupan sólo muestran parcialmente la configuración de otros mundos como totalidades naturales y/o sociales, a diferencia de otros tantos casos del género. Por el contrario, se concentran en las nuevas relaciones sociales e intersubjetivas surgidas entre humanos y robots. Se trata la construcción de nuevas alteridades, pero éstas son alteridades próximas, insertas en el mundo humano en la Tierra, alteridades de otros seres que se parecen a los humanos, de robots que adquieren la condición de la subjetividad humana.

De una u otra manera se evidencia la emergencia de nuevas subjetividades. En unos casos se destaca el proceso mismo de esa emergencia, en otros se lo presupone. El primer caso corresponde a la película Inteligencia artificial, en donde se muestra la emergencia de la subjetividad de David, el niño robot, bajo la forma de la construcción de un inconsciente y gracias a la travesía por la cual llega a identificar su deseo con la fantasía. El segundo, a El hombre bicentenario, donde se muestra el proceso social y técnico por el cual Andrew deviene sujeto pasando de robot a cyborg y de cyborg a humano. En Blade Runner y en Yo robot, en cambio, no se focaliza el proceso de constitución en sujetos de los robots, se destaca sí la condición subjetiva de los mismos pero el énfasis no está en mostrar el proceso. Sin embargo, en todos los casos se plantea el problema de

${ }^{16}$ Poíesis, en su múltiple acepción griega, como un pro-ducir, tanto la elaboración artesanal como la elaboración artístico-poetizante, traer-a-la-luz y poner- en-la-imagen (Heidegger, 1986). 
cómo un ser artificial, un sistema electrónico abierto y dinámico, puede devenir sujeto humano, poniéndose así en evidencia la condición misma artefactual del cuerpo y de la condición de sujeto. ${ }^{17} \mathrm{Si}$ a ser humano se llega como resultado de una construcción, se muestra que es posible pasar de la condición contingente de ser artificial a la condición de humano.

La idea del cuerpo artefactual ${ }^{18} \mathrm{y}$ del yo que se construye es una idea que sólo puede aparecer en un momento en el que el mismo cuerpo se considera parte constitutiva de la subjetividad, en el que se es el que se es con todo y cuerpo, una subjetividad encarnada que no admite su reducción a la polaridad privilegiada del dualismo occidental, el alma o el espíritu. Una sensibilidad de época posmoderna o sobremoderna, al mismo tiempo humanista y materialista. $Y$ es la técnica la mediación insustituible, la que hace visible esa condición poiética y autopoiética de lo humano. ${ }^{19}$ Ésta pone en evidencia algo que de tan natural resulta inadvertido, que el hombre es un producto artificial, una construcción de sí mismo, de su praxis. Sin la técnica el hombre no sería lo que es. Y, al mismo tiempo, al ponerse de presente que de sistemas dinámicos abiertos e inorgánicos los robots pueden devenir en sujetos humanos, la técnica devela la condición fundamental de lo humano, la de no tener esencia, la de construirse y reconstruirse en un movimiento social y técnico que no termina.

No hay lugar para un humanismo ingenuo. Qué sea lo humano es algo que no puede ser definido de antemano y de manera certera y, en cualquier caso, no puede ser pensado como algo absoluto, como una esencia. Antes bien, se ha hecho patente su condición artefactual, autopoiética y relacional (Kavanagh, 2003).

\footnotetext{
${ }^{17}$ Según Telote (1995) ese sería justamente el mayor aporte de la CF, el de evidenciar la condición artificial de lo humano mediante la exhibición del carácter artefactual del cuerpo.

${ }^{18}$ Un antecedente teórico muy importante de la noción de cuerpo artefactual es la idea de cuerpo sin órganos de Gillez Deleuze (1988) -inspirada en los sistemas abiertos y cerrados, orden, desorden y fluctuaciones- que postula la posibilidad de desestratificar el cuerpo para que no obedezca al mecanismo establecido que le prescribe cierto tipo de funcionamiento, romper la dominancia (moral, fisiológica) de una organización jerarquizada. Esto implica dejar de ser organismo, dejar de tener órganos especializados y abrirse a la posibilidad del libre agenciamiento sobre el propio cuerpo. Se trata de romper con la naturalización del cuerpo y con su cristalización orgánica para que llegue a ser, para que devenga algo heterogéneo y plástico y que, por ejemplo, pueda producir nuevos órganos.

${ }^{19}$ Noción que hace juego con otra que articula toda una visión antropológica, la del hombre como un "ser carencial", en el sentido de que no tiene órganos e instintos especializados. Por ello es inepto para la vida en cualquier ambiente natural y por lo tanto depende ante todo de la acción, de la transformación inteligente de cualquier circunstancia natural que se le presente. En consecuencia, ésta perspectiva concibe la relación entre hombre y técnica como una relación fundamental, que tiene que ver con la articulación entre la inteligencia inventiva del hombre, su equipamiento orgánico y la capacidad de aumento de sus necesidades (Gehlen, 1958).
} 


\section{Bibliografía}

- Adorno, Theodor y Max Horkheimer, 1994, Dialéctica de la Ilustración, Madrid: Trotta.

- Agamben, Giorgio, 2001, Infancia e historia: Destrucción de la experiencia y origen de la historia, Buenos Aires: Adriana Hidalgo Editora.

- Augé, Marc. 2004, Los no lugares. Espacios del anonimato: Una antropología de la sobremodernidad. Barcelona: Gedisa.

- Asimov, Isaac, 1999, Sobre la ciencia ficción, Buenos Aires: Sudamericana.

- Capanna, Pablo, 1996, El sentido de la ciencia ficción. Buenos Aires: Columbra. , 1992, El mundo de la ciencia ficción, Buenos Aires: Letra

Buena.

- Calabrese, Omar, 1987, La era neobarroca, Madrid: Cátedra.

- Ciocchini, Héctor y Luigi Volta, 1992, Monstruos y maravillas, Buenos Aires: Corregidor.

- Gehlen, Arnold, 1980, El hombre: su naturaleza y su lugar en el mundo, Salamanca: Sígueme.

- Habermas, Jurgen, 1993, El discurso filosófico de la modernidad, Madrid: Taurus.

- Haraway, Donna J. A., 1991, “Cyborg Manifesto: Science, Technology, and Socialist- Feminism in the Late Twentieeth Century", en: Haraway, Simians, Cyborgs, and Women: The Reinvention of Nature, New York: Routledge. , 2003, The companion species manifesto: Dogs, people, and significant othereness, Chicago: Prickly paradigm press.

- Heidegger, Martín, 1986, “La pregunta por la técnica”, en: Revista Universidad de Antioquia 205, septiembre de 1986.

- Kavanagh, James, 2003, "Feminism, Humanism and Science in Alien"en: Kuhn, Annette (ed.), Alien Zone: Cultural Theory and Contemporany Science Fiction Cinema, New York: Verso.

- Link, Daniel, 1993, Escalera al cielo: utopía y ciencia ficción, Colección cuadernillos de género, La marca Editora: Buenos Aires.

- Said, Edward, 2006, Orientalismo, De bolsillo: Barcelona.

- Santelia, A., 2003 (1914), "La arquitectura futurista”, en: Marinetti et al, Futurismo. Manifiestos y textos. Buenos Aires: Quadrata. 
- Springer, Claudia, 1996, Electronic Eros: Bodies and Desire in the Postindustrial Age, Austin: University of Texas Press.

- Steimberg, Oscar, 1998, Semiótica de los medios masivos: El pasaje a los medios de los géneros populares. Buenos Aires: Autel.

- Telotte, J. P., 1999, A Distant Technology: Science Fiction Film and the Machine Age, Hanover and London: Wesleyan University Press.

,1995, Replications: A Robotic History of the Science Fiction Film, Urbana and Chicago: University of Illinois Press.

- Traverse, Oscar, 1986, "Carmen, la de las transposiciones", 1er Congreso Nacional de Semiótica, La Plata, Argentina.

- Wellmer, Albrech, 1993, Sobre la dialéctica de modernidad y posmodernidad: La crítica de la razón después de Adorno, Madrid: Visor. 
